\title{
PIRÂMIDE ALIMENTAR ADAPTADA: GUIA PARA ESCOLHA DOS ALIMENTOS
}

\section{ADAPTED FOOD PYRAMID: A GUIDE FOR A RIGHT FOOD CHOICE}

\author{
Sonia Tucunduva PHILIPPI' \\ Andrea Romero LATTERZA ${ }^{2}$ \\ Ana Teresa Rodrigues CRUZ ${ }^{3}$ \\ Luciana Cisotto RIBEIRO ${ }^{4}$
}

\begin{abstract}
RESUMO
Este trabalho traz a avaliação e adaptação da pirâmide alimentar elaborada nos Estados Unidos em 1992 à realidade profissional brasileira dos grupos de pesquisa em alimentação e nutrição. A Pirâmide Alimentar Adaptada foi construída com os alimentos distribuídos em oito grupos (cereais, frutas, vegetais, leguminosas, leite, carnes, gorduras e açúcares) de acordo com a contribuição de cada nutriente básico na dieta. Foram estabelecidas três dietas-padrão (1 600 kcal, 2200 kcal e 2800 kcal), com distribuição dos macronutrientes: carboidratos (50-60\%), proteínas (1015\%), lipídios (20-30\%). Cada nível foi apresentado em porções mínimas e máximas a serem consumidas de acordo com as dietas referidas. Para o cálculo das dietas e definição das porções utilizou-se o software "Virtual Nutri”. A Pirâmide Alimentar Adaptada pode ser utilizada como instrumento para orientação nutricional de indivíduos e grupos populacionais, respeitando-se os hábitos alimentares e as diferentes realidades regionais e institucionais.
\end{abstract}

Termos de indexação: dietética, orientação nutricional, pirâmide alimentar, guia alimentar, dieta, alimentos, consumo de alimentos.

\section{ABSTRACT}

This paper intends to evaluate and adapt the Food Pyramid made in USA in 1992 to the Brazilian professional reality of research groups in food and nutrition. The Adapted Food Pyramid was established with foods distributed in eight groups according to each basic nutrient contribution in the diet (cereals, fruits, vegetables, beans, milk, meat, fat and sugar). To reach this Adapted Food Pyramid model it was established three standard diets (1600 kcal, $2200 \mathrm{kcal}$ and $2800 \mathrm{kcal})$ with the following macronutrients distribution: carbohydrates (50-60\%), protein (10-15\%) and fat (20-30\%). Each level was presented

\footnotetext{
(1) Departamento de Nutrição, Faculdade de Saúde Pública, Universidade de São Paulo.

(2) Mestranda da Faculdade de Saúde Pública, Universidade de São Paulo.

(3) Bolsista FAPESP.

(4) Bolsista PIBIC-CNPq.
} 
with " the minimum and the maximum" portion to be consumed according to the standard diet reported. The "Virtual Nutri" software was applied to obtain the data of this paper. This Pyramid is a contribution for nutritional orientation for individuals and population groups according to food habits and different regional and institutional.

Index terms: dietetics, nutritional orientation, food pyramid, feeding guide, diet, food, food consumption.

\section{INTRODUÇÃO}

O avanço na ciência da alimentação e nutrição tem se tornado constante nos últimos anos, e estes estudos geram resultados que devem ser usados para a melhoria da qualidade de vida da população (Welsh et al., 1992a).

No século passado, Atwater foi pioneiro na investigação nutricional e o primeiro a desenvolver vários dos componentes necessários para a elaboração de guias alimentares. Em 1894, ele publicou tabelas de composição de alimentos e padrões dietéticos para a população norte-americana, dando início às bases científicas para estabelecer relações entre a composição dos alimentos, consumo e saúde dos indivíduos. A partir daí, foram propostos vários guias para diversos grupos populacionais com diferentes formas de apresentação. O conteúdo destes também foi modificado devido às novas concepções sobre alimentos, como por exemplo, o consumo de gorduras e açúcares que é variável, conforme a população à qual se destina o guia (Welsh et al., 1992a).

Tem se procurado uma forma gráfica de distribuição dos alimentos para uma melhor compreensão por parte da população, ou seja, fazer com que haja o consumo de vários alimentos e em quantidade suficiente para que juntos componham uma dieta adequada nutricionalmente (Welsh et al., 1992b).

Nos Estados Unidos, após pesquisa para verificar qual forma gráfica era mais aceita pela população, observou-se que a distribuição dos alimentos em forma de "roda" não surtia os resultados esperados, pois inicialmente mostrava os alimentos divididos conforme função e com a mesma área, possibilitando diferentes interpretações. Além disto, trata-se de uma representação ultrapassada porque, segundo os entrevistados, as informações já eram conhecidas (Welsh et al., 1992b).

Foram testadas várias formas de apresentar os alimentos: em pilhas, em utensílios (xícara, tigela, prato), em carrinho de supermercado e, finalmente como pirâmide, que foi a adotada pelo United States Department of Agriculture (USDA) em 1992.

Achterberg et al. (1994) descrevem que a Pirâmide Alimentar é um instrumento de orientação nutricional utilizado por profissionais com objetivo de promover mudanças de hábitos alimentares visando a saúde global do indivíduo e a prevenção de doenças. Neste trabalho aborda-se como colocar em prática os princípios da Pirâmide Alimentar, que é uma representação gráfica facilitadora para a visualização dos alimentos assim como a sua escolha nas refeições do dia (Welsh et al., 1992b).

A Pirâmide Alimentar norte-americana (Welsh et al., 1992b) é baseada em sete pontos principais:

- Ingestão de uma dieta variada em alimentos;

- Manutenção do "peso ideal";

- Dieta pobre em gorduras, gorduras saturadas e colesterol;

- Dieta rica em vegetais, frutas, grãos e produtos derivados dos grãos;

- Açúcar com moderação;

- Sal e sódio com moderação,

- Bebidas alcoólicas com moderação.

Para o desenvolvimento de guias alimentares deve haver um processo de pesquisa contendo: o diagnóstico da situação nutricional e dados epidemiológicos que fundamentem as dietas, os objetivos, as metas nutricionais e um banco de dados contendo a composição dos alimentos escolhidos.

Os guias alimentares devem:

- Promovere manter a saúde global do indivíduo com orientações direcionadas para prevenção ou tratamento de qualquer doença;

- Ser baseados em pesquisas atualizadas;

- Ter uma visão global da dieta;

- Ser úteis para o público alvo; 
- Encontrar uma forma realista de suprir as necessidades nutricionais utilizando-se da dieta habitual de cada população;

- Ser práticos e, os nutrientes e energia adaptados segundo a idade, o sexo e a atividade física,

- Ser dinâmicos, permitindo o máximo de flexibilidade para a escolha dos alimentos, a fim de suprir as necessidades nutricionais do indivíduo (Welsh et al., 1992b).

No Brasil, até a década de 1980, os "grupos de alimentos" atendiam aos objetivos propostos nas tabelas de recomendação e a representação gráfica mais usual foi sempre como "roda de alimentos". O Instituto de Saúde, da Secretaria de Saúde do Estado de São Paulo, em 1974, publicou um documento (Kalil et al., 1974) em que recomendava, ao invés da "roda de alimentos", a representação dos alimentos fosse em grupos. Na época foi um avanço a adoção dos seis grupos para programas de orientação nutricional: 1) leites, queijos, coalhada, iogurtes; 2) carnes, ovos, leguminosas; 3) hortaliças; 4) cereais e feculentos; 5) frutas; 6) açúcares e gorduras, dando uma maior flexibilidade para o momento da orientação nutricional.

Os guias alimentares são instrumentos de orientação e informação à população visando promover saúde e hábitos alimentares saudáveis. Os guias devem ser representados por grupos de alimentos, e são baseados na variedade de informações incluindo a relação existente entre os alimentos e a saúde dos indivíduos. Com um guia alimentar adequado à população os objetivos propostos podem ser alcançados (Spiller, 1993).

A introdução da Pirâmide Alimentar para a população americana e a repercussão favorável da apresentação dos alimentos em porções, foram fatores decisivos para a proposta de adaptação à nossa população. A simples tradução do material e sua aplicação em orientação nutricional não refletem a realidade da população, daí justifica-se a adaptação da pirâmide não só em termos de apresentação dos alimentos em níveis e em porções recomendadas, mas também na escolha de alimentos da dieta usual e do hábito alimentar.

\section{MATERIAL E MÉTODOS}

Após levantamento bibliográfico e estudos comparativos sobre representação gráfica de diferentes guias alimentares, optou-se pela Pirâmide Alimentar proposta nos Estados Unidos (United..., 1992). A partir da pirâmide alimentar norte-americana e conforme dietas-padrão estabelecidas em nosso meio, foi desenvolvida uma nova pirâmide, com distribuição e caracterização dos alimentos nela contidos.

Para cada dieta foram estabelecidas porções em função dos grupos dos alimentos. A quantidade de energia (kcal) depende de fatores como idade, sexo, altura, nível de atividade física, entre outros. A dieta de $1600 \mathrm{kcal}$ foi calculada para mulheres com atividade física sedentária (como ler, ver televisão, usar o computador) e adultos idosos. A dieta com $2200 \mathrm{kcal}$ pode ser aplicada para crianças, adolescentes do sexo feminino, mulheres com atividade física intensa (como correr, andar de bicicleta, fazer ginástica aeróbica) e homens com atividade física sedentária. Com relação as gestantes e nutrizes ao se usar como referência $2200 \mathrm{kcal}$, observar o acréscimo energético recomendado (National..., 1989). A dieta de $2800 \mathrm{kcal}$ foi calculada para homens com atividade física intensa e adolescentes do sexo masculino (Wilkening et al., 1994)

As dietas foram elaboradas com alimentos típicos e do hábito alimentar e distribuídos em seis refeições (café da manhã, lanche da manhã, almoço, lanche da tarde, jantar e lanche da noite). Foram selecionados os alimentos e as preparações mais habituais nos estudos de consumo alimentar (Mondini \& Monteiro, 1994; Galeazzi et al., 1997). Os dados utilizados para o cálculo das dietas-padrão foram retirados do banco de dados do software "Virtual Nutri”" (Philippi et al., 1996), que possui informações de alimentos in natura; de preparações com alimentos básicos da dieta realizadas no Laboratório de Técnica Dietética e de alimentos industrializados, cujos dados foram obtidos diretamente nos Centros de Informação ao Consumidor das empresas e de coleta de dados para levantamento de rótulos de embalagens.

As porções foram estabelecidas por refeição, de acordo com o total de energia de cada alimento e das dietas (1 600, 2200 e $2800 \mathrm{kcal}$ ), respeitando-se o mínimo e o máximo de porções.

Foram elaboradas tabelas de alimentos com os equivalentes (em energia) de cada nível de alimentos da pirâmide, com as respectivas porções em medidas caseiras e em gramas possibilitando as indicações para as substituições (Esha..., 1992; Philippi et al., 1996). 


\section{RESULTADOS}

Para cada dieta estabelecida foram obtidas para proteínas (10 a 15\%), carboidratos (50 a 60\%) e lipídios (20 a 30\%), as distribuições percentuais discriminadas na Tabela 1, considerando-se, praticamente, todos dentrodos intervalos preconizados:

Tabela 1. Dieta.

\begin{tabular}{lccc}
\hline Dietas (kcal) & Proteínas & Carboidratos & Lipídios \\
\cline { 2 - 3 } & & $\%$ & \\
\cline { 2 - 4 } 1600 & 15 & 61 & 23 \\
2200 & 14 & 58 & 27 \\
2800 & 15 & 60 & 25 \\
\hline
\end{tabular}

Pôde-se ainda observar, nos Anexos 1, 2 e 3, os alimentos componentes das diferentes dietas, distribuídos nas seis refeições com os pesos em gramas, as medidas caseiras, as porções e os grupos a que pertencem os alimentos de acordo com os níveis da pirâmide.

Ao se analisar a pirâmide original proposta nos Estados Unidos em 1992 pelo USDA, observa-se que o tipo, consumo e modo de preparo de alimentos nos Estados Unidos e no Brasil diferem bastante. Decidiu-se usar a estrutura da pirâmide, pois expressa de forma clara como escolher os alimentos que devem ser consumidos, mas foi necessário adaptá-la aos alimentos disponíveis em nosso país e aos hábitos alimentares. níveis:

A pirâmide proposta foi dividida então, quatro

- $1^{\circ}$ nível: grupo dos cereais, tubérculos, raízes;

- $2^{\circ}$ nível: grupo das hortaliças e grupo das frutas;

- $3^{\circ}$ nível: grupo do leite e produtos lácteos; grupo das carnes e ovos e grupo das leguminosas,

- $4^{\circ}$ nível: grupo dos óleos e gorduras e grupo dos açúcares e doces.

Os oito grupos foram compostos com alimentos semelhantes e foi definido o número de porções diárias para cada grupo (os valores das porções estão de acordo com as dietas-padrão calculadas). Com relação ao leite, foram estabelecidas para as três dietas, três porções visando atender as recomendações mínimas de cálcio sem referência à porções mínimas e máximas. Ao se consumir um número de porções além de três, existe a possibilidade de exceder o total energético determinado para cada dieta-padrão. O mesmo raciocínio se aplica para o caso das leguminosas. Os alimentos foram distribuídos em oito grupos (Figura 1):

- Pães, cereais, raízes e tubérculos (pães, farinhas, massas, bolos, biscoitos, cereais matinais, arroz, feculentos e tubérculos: 5 porções no mínimo a 9 no máximo);

- Hortaliças (todas as verduras e legumes, com exceção das citadas no grupo anterior: 4 porções no mínimo, 5 no máximo);

- Frutas (cítricas e não cítricas: 3 porções no mínimo, 5 no máximo);

- Carnes (carne bovina e suína, aves, peixes, ovos, miúdos e vísceras: 1 porção no mínimo, 2 no máximo);

- Leite (leites, queijos e iogurtes: 3 porções);

- Leguminosas (feijão, soja, ervilha, grão de bico, fava, amendoim: 1 porção);

- Óleos e gorduras (margarina/manteiga, óleo: 1 porção no mínimo, 2 no máximo);

- Açúcares e doces (doces, mel e açúcares: 1 porção no mínimo, 2 no máximo).

\section{DISCUSSÃO}

A porção dos cereais proposta é menor do que a preconizada inicialmente na pirâmide original. Assim, o número de porções consumidas em um dia é de: 5 a 9 porções na pirâmide modificada e de 6 a 11 porções na original proposta pelo USDA (United..., 1992).

Devido às frutas e hortaliças serem alimentos comuns à dieta e de fácil acesso para a população brasileira, as porções foram aumentadas para 3 a 5 porções no grupo das frutas e para 4 a 5 porções no grupo das hortaliças.

Na Pirâmide norte-americana as carnes, ovos e leguminosas encontram-se dentro de um mesmo grupo. Devido às leguminosas serem comuns na alimentação básica do brasileiro, principalmente o feijão, achou-se conveniente colocá-las a parte, uma vez que não possuem os mesmos valores nutritivos que carnes e ovos e são os produtos isolados que mais contribuem para o consumo de proteínas, não podendo ser substituídas uma pela outra, sem o necessário ajuste no equilíbrio de aminoácidos, que é dado pelo consumo simultâneo deste alimento com o arroz (Tagle, 1981). As oleaginosas, tipo amendoim, com alto valor energético foram também incluídas neste grupo apesar do baixo consumo nas dietas habituais 


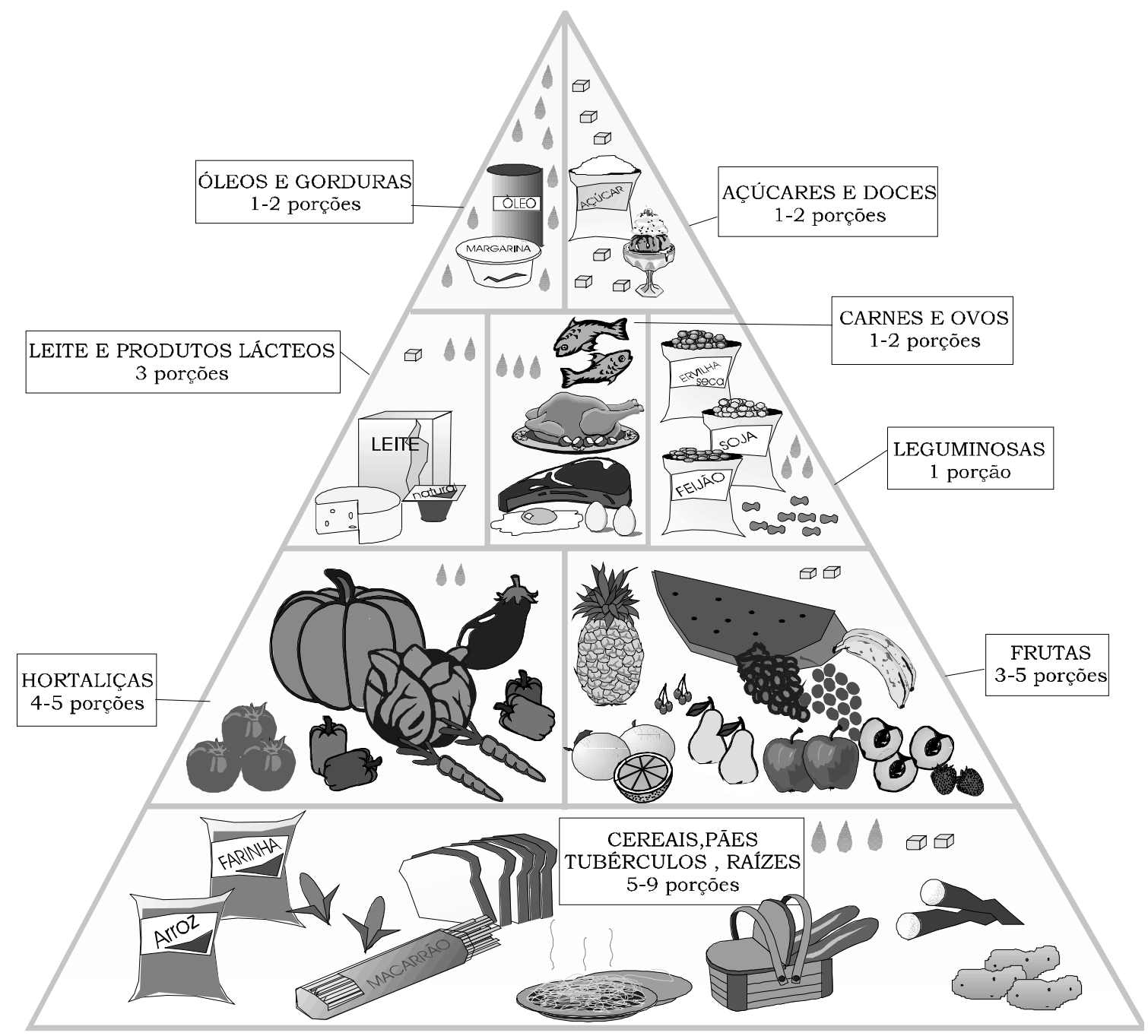

Figura 1. Pirâmide alimentar adaptada

Fonte: PHILIPPI,S.T. et al,1996

Ilustração: Graziela Mantoanelli

Dados de porções: software "Virtual Nutri"

Legenda: (naturalmente presente ou adicionada)

Gordura

$\boxminus$ Açúcar 
Os alimentos como leite, carnes e leguminosas encontram-se no terceiro nível da pirâmide, por serem todos de origem protéica devendo ser consumidos na proporção de 10 a $15 \%$ do valor energético total (VET), não significando, no entanto, que possam ser substituídos entre si.

A batata e a mandioca foram incluídas com os pães e cereais por constituírem fonte de carboidratos.

O leite mereceu atenção especial pelo fato de ser fonte de cálcio, micronutriente importante em todas as fases da vida. Com três porções diárias de leite consegue-se, em média, $800 \mathrm{mg}$ de cálcio, suficientes para cobrir as necessidades exigidas para adultos e crianças. É preciso no entanto, aumentar o consumo de alimentos fontes de cálcio para gestantes, nutrizes e adolescentes (National..., 1989).

Os alimentos como óleos e gorduras, açúcares e doces devem ter seu consumo moderado, uma vez que já existem de forma natural, de composição ou de adição, em vários alimentos e preparações. As legendas para óleos (gota) e açúcares (cubo) estão distribuídas por todos os níveis da pirâmide.

Os óleos e gorduras (1 a 2 porções) e os açúcares (1 a 2 porções) foram colocados separadamente e tiveram suas porções determinadas, para facilitar a orientação sobre a quantidade moderada a ser adicionada na dieta.

Os alimentos in natura são facilmente identificados e classificados na Pirâmide Alimentar, o que não acontece com as preparações. Ao se utilizar como exemplo uma preparação culinária do tipo "lasanha com molho quatro queijos", podem ser contabilizadas uma porção do grupo de cereais (massa da lasanha) e uma do grupo do leite (molho com leite e queijos), uma vez que existe mais de um tipo de alimento (ingrediente) presente neste exemplo.

Dependendo do grupo populacional com o qual se trabalha há necessidade de alertar para os riscos à saúde resultantes do uso indiscriminado dos alimentos como óleo, gorduras, açúcares e doces. Ao se considerar as formas habituais de preparo das refeições, constata-se preferências por frituras, assim como por sobremesas bem doces, bebidas com açúcar, além de óleos e gorduras utilizados para refogar e temperar alimentos como arroz, feijão e saladas.

Visando complementar a orientação nutricional, baseada na pirâmide alimentar, foram definidas algumas recomendações básicas:
- Escolher uma dieta variada com alimentos de todos os grupos da Pirâmide;

- Dar preferência aos vegetais como frutas, verduras e legumes;

- Ficar atento ao modo de preparo dos alimentos para garantia de qualidade final, dando prioridade aos alimentos em sua forma natural, e à preparações assadas, cozidas em água ou vapor, e grelhadas;

- Ler os rótulos dos alimentos industrializados para conhecer o valor nutritivo do alimento que será consumido;

- Medidas radicais não são recomendadas e os hábitos alimentares devem ser gradativamente modificados;

- Utilizar açúcares, doces, sal e alimentos ricos em sódio com moderação;

- Consumir alimentos com baixo teor de gordura. Preferir gorduras insaturadas (óleo vegetal e margarina), leite desnatado e carnes magras;

- Se fizer uso de bebidas alcóolicas, fazer com moderação,

- Para programar a dieta e atingir o peso ideal considerar o estilo de vida e a energia diária necessária.

Os oito grupos da Pirâmide com os alimentos e seus equivalentes em porções (medidas caseiras e gramas) estão apresentados nos Anexos 4 a 11 com o objetivo de definir os alimentos substitutos componentes de uma dieta qualitativa e quantitativamente equilibrada e seus equivalentes em energia.

\section{CONCLUSÃO}

Com base em dietas pré-estabelecidas, adaptouse a pirâmide alimentar norte-americana à realidade da nossa população, servindo como guia para escolha dos alimentos e definição das porções na composição de uma dieta saudável.

A representação gráfica dos alimentos na forma de pirâmide deve ser dinâmica, considerando-se a especificidade do grupo populacional com o qual se trabalha (crianças, adultos, adolescentes, idosos e outros).

A quantificação dos alimentos equivalentes apresentada se constitui em importante ferramenta na formulação de dietas como subsídio para guias 
alimentares, como informativo, pois estão apresentados de forma clara, possibilitando fácil entendimento e aplicação.

A definição de alimentos substitutos em energia não deve ser vista como a única estratégia de orientação nutricional individual ou para grupos populacionais. Há necessidade de se desenvolver pesquisas semelhantes para definir e quantificar os alimentos substitutos e equivalentes para os demais nutrientes-fonte, tais como: lipídios, ferro, vitaminas e outros.

É importante que a pirâmide alimentar seja sempre avaliada e adaptada em função dos objetivos a que se destina, da população a ser atingida, respeitando-se a disponibilidade de alimentos e os hábitos alimentares locais, mantendo-se como um guia prático de orientação nutricional.

\section{AGRADECIMENTOS}

Pela valiosa colaboração das professoras Regina Mara Fisberg e Ana Maria Cervatto, das bolsistas PIBIC/ CNPq Ana Carolina Almada Colucci e Graziela Mantoaneli e as bolsistas da FAPESP Cláudia Luciana Leite e Bettina Brasil.

\section{REFERÊNCIAS BIBLIOGRÁFICAS}

ACHTERBERG,G,McDONNELL,E.,BAGBY,R.How toput the food guide into pratice. Journal of American Dietetic Association, Chicago, v.94, n.9, p.1030-1035, 1994.

ESHA RESEARCH. The food processor: computerized nutrition system, (software). Version 5.0 for Windows. Salen, Oregon, 1992.

GALEAZZI, M.A.M., DOMENE, S.M.A., SICHIERI, R. Estudo multicêntrico sobre consumo alimentar. Cadernos de Debate, Campinas, volume especial, 1997.
(Núcleo de Estudo e Pesquisas em Alimentação e Nutrição, UNICAMP).

KALIL, A.C., PHILIPPI, S.T., LERNER, B.R., KUROBA, C.H., BOOG, M.C.F., ROSA, M.L., SOBRINHO, O.N.N., LEPPER, R.M., FARIA, Z. Grupo de Alimentos. Revista ABIA/SAPRO, São Paulo, v.11, p.38-44, 1974.

MONDINI, L., MONTEIRO, C.A. Mudanças no padrão de alimentação da população urbana brasileira (19621988). Revista de Saúde Pública, São Paulo, v.28, n.6, p.433-439, 1994.

NACIONAL RESEARCH COUNCIL (USA). Recommended Dietary Allowances. 10.ed. Washington DC: National Academy Press, 1989.284p.

PHILIPPI, S.T., SZARFARC, S.C., LATTERZA, A.R. Virtual Nutri (software) versão 1.0 for Windows. Departamento de Nutrição da Faculdade de Saúde Pública da Universidade de São Paulo, 1996.

SPILLER, G. The super pyramid. Washington DC : Times Books, 1993.

TAGLE, M.A. Nutrição. São Paulo : Artes Médicas, 1981. $234 \mathrm{p}$.

UNITED STATES DEPARTMENT OFAGRICULTURE. Human Nutrition Information Service. The food guide pyramid. Hyattsville, 1992. [folder].

WELSH, S., DAVIS, C., SHAW, A. A brief history of food guides in the United States. Nutrition Today, Annapolis, v.27, n.6, p.6-11, 1992a.

WELSH, S., DAVIS, C., SHAW, A. Development of the food guide pyramid. Nutrition Today, Annapolis, v.27, n.6, p.12-23, 1992b.

WILKENING, V.,DEXTER,P.,LEWIS, C.Labelling foods to improve nutrition in the United States. Food Nutrition and Agriculture, Rome, v.4, n.10, p.38-43, 1994.

Recebido para publicação em 29 de outubro de 1997 e aceito em 17 de agosto de 1998. 


\section{ANEXOS}

\section{ANEXO1}

\section{Dieta para indivíduo adulto com 1600 kcal}

\section{ALIMENTO}

Café da manhã

Leite desnatado

Café (infusão)

Açúcar refinado

Biscoito água e sal

Geléia

Requeijão

Suco de laranja

Lanche da manhã

Banana-nanica

\begin{abstract}
Almoço
Macarrão ao sugo

Brócolis cozido

Óleo de soja

Lanche da tarde

Bolo simples

Chá (infusão)

Açúcar refinado
\end{abstract}

Queijo parmesão ralado

\section{Jantar}

Alface

Tomate

Ervilha

Azeite de oliva

Arroz branco cozido

Feijão (50\% grão/caldo)

Carne assada

Batata cozida

Vagem cozida

Suco de laranja

Lanche da noite

Iogurte polpa de fruta
PESO (g)

MEDIDA CASEIRA**

1 xícara de chá

1 xícara de café

$1 / 2$ colher de sobremesa

4 unidades

1 colher de sobremesa

2 pontas de faca

$3 / 4$ copo de requeijão

1 unidade

2 escumadeiras

$1 / 4$ colher de sopa

1 escumadeira

1 colher de sobremesa

1 fatia

1 xícara de chá

$1 / 2$ colher de sobremesa

4 folhas

1 unidade

2 colheres de sopa

1 colher de sobremesa

3 colheres de sopa

2 colheres de sopa

1 fatia

$1 / 2$ unidade

2 colheres de sopa

1 copo de requeijão
PORÇÃO/GRUPO

Leite

*

Açúcares

Cereais

Açúcares

Leite

Frutas

Frutas

Cereais

Leite

Hortaliças

Óleos

Cereais

*

Açúcares

Hortaliças

Hortaliças

Leguminosas

Óleos

Cereais

Leguminosas

Carnes

Cereais

Hortaliças

Frutas

Leite

Energia total: $1596.56 \mathrm{kcal}$

*O café e o chá foram considerados "bebidas" sem definição de porção e grupo.

** Dados obtidos do software "Virtual Nutri" 


\section{ANEXO2}

\section{Dieta para indivíduo adulto com 2200 kcal}

\section{ALIMENTO}

Café da manhã

Leite desnatado

Café (infusão)

Açúcar refinado

Biscoito água e sal

Geléia

Requeijão

Melão

Lanche da manhã

Banana-nanica

\section{Almoço}

Macarrão ao sugo

Queijo parmesão ralado

Brócolis cozido

Óleo de soja

Morango fresco

\section{Lanche da tarde}

Biscoito água e sal

Margarina/manteiga

Chá (infusão)

Açúcar refinado

Jantar

Alface

Tomate

Azeite de oliva

Arroz branco cozido

Feijão (50\% grão/caldo)

Carne assada

Batata frita

Vagem cozida

Laranja

Lanche da noite
PESO (g)

MEDIDA CASEIRA**

1 xícara de chá

1 xícara de café

$1 / 2$ colher de sopa

4 unidades

$1 \frac{1}{2}$ colher de sobremesa

2 pontas de faca

1 fatia

1 unidade

4 escumadeiras

$1 / 4$ colher de sopa

1 escumadeira

1 colher de sobremesa

6 unidades

4 unidades

$1 / 2$ colher de sobremesa

1 xícara de chá

$1 / 2$ colher de sopa

6 folhas

1 unidade

1 colher de sobremesa

$4 \frac{1}{2}$ colheres de sopa

4 colheres de sopa

1 fatia grande

1 escumadeira

2 colheres de sopa

1 unidade

\section{PORÇÃO/GRUPO}

1

$*$

Leite

*

Açúcares

Cereais

Açúcares

Leite

Frutas

Frutas

Cereais

Leite

Hortaliças

Óleos

Frutas

Cereais

Óleos

*

Açúcares

$11 / 2 \quad$ Hortaliças

1 Hortaliças

$1 / 2$ Óleos

$1 \frac{1 / 2}{2} \quad$ Cereais

1 Leguminosas

$1 \frac{1 / 2}{1} \quad$ Carnes

$1 \frac{1 / 2}{2} \quad$ Cereais

1 Hortaliças

$1 \quad$ Frutas

Energia total: $2170.76 \mathrm{kcal}$

*O café e o chá foram considerados "bebidas" sem definição de porção e grupo.

** Dados obtidos do software "Virtual Nutri". 


\section{ANEXO3}

\section{Dieta para indivíduo adulto com $2800 \mathrm{kcal}$}

\section{ALIMENTO}

Café da manhã

Leite tipo C

Café (infusão)

Açúcar refinado

Pão francês

Margarina/manteiga

Mamão papaya

Lanche da manhã

Vitamina de leite e frutas

Almoço

Pão francês

Macarrão ao sugo

Queijo parmesão ralado

Brócolis cozido

Óleo de soja

Morango fresco

\section{Lanche da tarde}

Biscoito água e sal

Geléia

Chá (infusão)

Açúcar refinado

Jantar

Alface

Tomate

Azeite de oliva

Arroz branco cozido

Feijão (50\% grão/caldo)

Carne assada

Batata frita

Vagem cozida

Laranja

Lanche da noite

Pão francês

Requeijão

Suco de maracujá com açúcar
PESO (g)

MEDIDA CASEIRA**

1 xícara de chá

1 xícara de café

$1 / 2$ colher de sopa

1 unidade

1 colher de sobremesa

$1 / 2$ unidade

250

50

280

3

60

3

72

24

23

142

14

48

163

5

140

105

140

100

44

185

\section{0}

20

200
1 copo

1 unidade

4 escumadeiras

$1 / 4$ colher de sopa

1 escumadeira

1 colher de sobremesa

6 unidades

4 unidades

$1 \frac{1}{2}$ colher de sobremesa

1 xícara de chá

$1 / 2$ colher de sopa

6 folhas

$1 \frac{1}{2}$ unidade

1 colher de sobremesa

$4^{1 / 2}$ colheres de sopa

4 colheres de sopa

2 fatias

1 escumadeira

2 colheres de sopa

1 unidade

1 unidades

2 pontas de faca

1 copo dos de requeijão

\section{PORÇÃO/GRUPO}

Leite

*

Açúcares

Cereais

Óleos

Frutas

Frutas

Leite

Cereais

Cereais

Leite

Hortaliças

Óleos

Frutas

Cereais

Açúcares

*

Açúcares

$1 \frac{1}{2} \quad$ Hortaliças

$1 \frac{1}{2} \quad$ Hortaliças

$1 / 2$ Óleos

$1 \frac{1 / 2}{2} \quad$ Cereais

1 Leguminosas

2 Carnes

$1 \frac{1 / 2}{2} \quad$ Cereais

1 Hortaliças

$1 \quad$ Frutas

$\begin{array}{ll}1 & \text { Cereais } \\ 3 / 4 & \text { Leite } \\ 1 & \text { Frutas } \\ 1 / 2 & \text { Açúcares }\end{array}$

Energia total: $2764.11 \mathrm{kcal}$

O café e o chá foram considerados "bebidas" sem definição de porção e grupo.

** Dados obtidos do software "Virtual Nutri" 


\section{ANEXO4}

\section{Pães, Cereais, Raízes e Tubérculos. $(\mathrm{n}=46)$} 1 porção $=150 \mathrm{kcal}$

\section{ALIMENTOS}

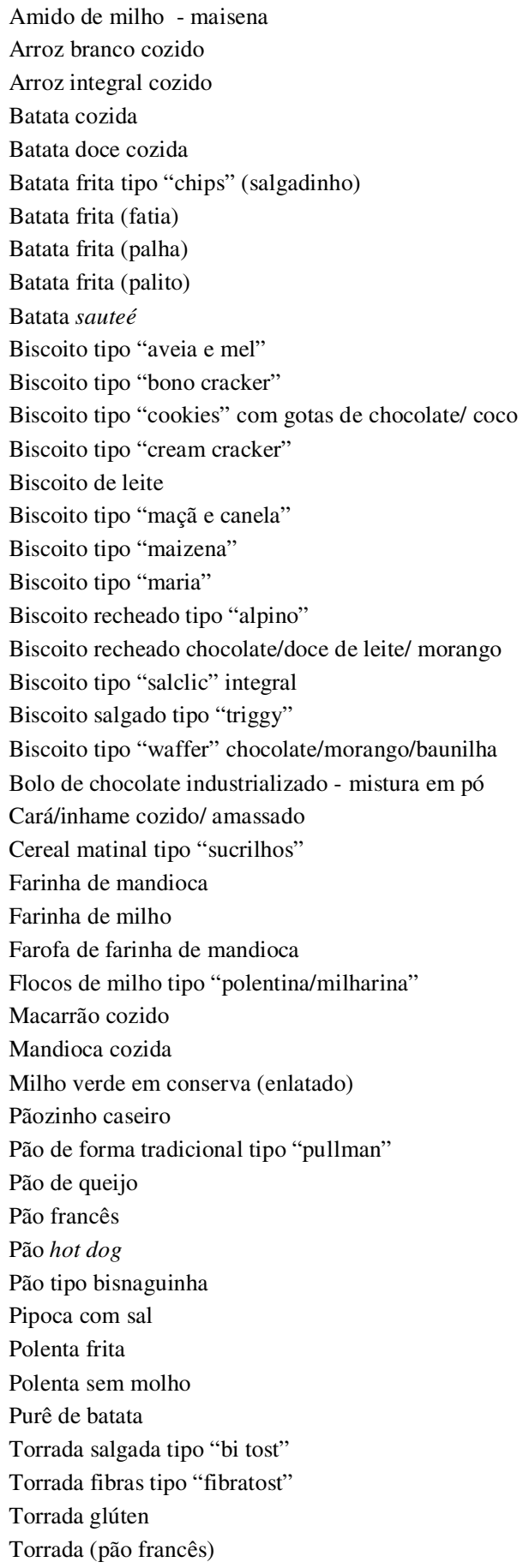

\section{PESO (g)}

\begin{tabular}{|c|c|}
\hline 40,0 & $21 / 2$ colheres de sopa \\
\hline 125,0 & 4 colheres de sopa \\
\hline 140,0 & 4 colheres de sopa \\
\hline 175,0 & $1 \frac{1}{2}$ unidade \\
\hline 150,0 & $1 \frac{1}{2}$ colheres de servir \\
\hline 27,0 & $1 / 3$ pacote \\
\hline 50,0 & 2 colheres de servir \\
\hline 29,0 & 1 colher de servir \\
\hline 58,0 & $11 / 3$ colher de servir \\
\hline 130,0 & $2 \frac{1}{2}$ colheres de servir \\
\hline 30,0 & 5 unidades \\
\hline 32,0 & 8 unidades \\
\hline 30,0 & 6 unidades \\
\hline 32,5 & 5 unidades \\
\hline 32,5 & 5 unidades \\
\hline 33,0 & 6 unidades \\
\hline 35,0 & 7 unidades \\
\hline 35,0 & 7 unidades \\
\hline 30,0 & 2 unidades \\
\hline 34,0 & 2 unidades \\
\hline 30,0 & 6 unidades \\
\hline 34,5 & 7 unidades \\
\hline 30,0 & 3 unidades \\
\hline 50,0 & 1 fatia \\
\hline 126,0 & $3 \frac{1}{2}$ colher de sopa \\
\hline 43,0 & 1 xícara de chá \\
\hline 48,0 & 3 colheres de sopa \\
\hline 48,0 & 4 colheres de sopa \\
\hline 37,0 & $1 / 2$ colher de servir \\
\hline 45,0 & $21 / 2$ colheres de sopa \\
\hline 105,0 & $31 / 2$ colheres de sopa \\
\hline 96,0 & 3 colheres de sopa \\
\hline 142,0 & 7 colheres de sopa \\
\hline 55,0 & $1 / 2$ unidade \\
\hline 43,0 & 2 fatias \\
\hline 40,0 & 1 unidade \\
\hline 50,0 & 1 unidade \\
\hline 75,0 & $1 \frac{1 / 2}{2}$ unidade \\
\hline 80,0 & 4 unidades \\
\hline 22,5 & 2 11/2 xícara de chá \\
\hline 60,0 & $1 \frac{1 / 2}{\text { fatia }}$ \\
\hline 200,0 & 2 fatias \\
\hline 135,0 & 2 colheres de servir \\
\hline 40,0 & 4 unidades \\
\hline 45,0 & 4 unidades \\
\hline 50,0 & 5 unidades \\
\hline 33,0 & 6 fatias \\
\hline
\end{tabular}

\section{MEDIDA CASEIRA}

$1 / 2$ colheres de sopa

4 colheres de sopa

$1 \frac{1}{2}$ unidade

$1 / 3$ pacote

colher de servir

$11 / 3$ colher de servir

5 unidades

unidades

fatia

3 colheres de sopa

olheres de sopa

6 fatias 


\section{ANEXO5}

Hortaliças. $(\mathbf{n}=\mathbf{5 0})$

1 porção $=15 \mathrm{kcal}$

\section{ALIMENTOS}

Abóbora cozida (menina, japonesa, moranga)

Abobrinha cozida

Acelga cozida

Acelga crua (picada)

Agrião

Aipo cru

Alcachofra (coração) cozido

Alcachofra cozida

Alface

Almeirão

Aspargos em conserva

Aspargos fresco cozido

Berinjela cozida

Beterraba cozida

Beterraba crua ralada

Brócolis cozido

Broto de alfafa cru

Broto de bambu cru

Broto de feijão cozido

Cenoura cozida (fatias)

Cenoura cozida (picada)

Cenoura crua (picada)

Chuchu cozido

Cogumelo em conserva

Couve-de-bruxelas cozida

Couve-flor cozida

Couve manteiga cozida

Ervilha em conserva

Ervilha fresca

Ervilha torta (vagem)

Escarola

Espinafre cozido

Jiló cozido

Mostarda

Palmito em conserva

Pepino japonês

Pepino picado

Picles em conserva

Pimentão cru fatiado (vermelho/verde)

Pimentão cru picado (vermelho/verde)

\section{Rabanete}

Repolho branco cru (picado)

Repolho cozido

Repolho roxo cru (picado)

Rúcula

Salsão cru

Tomate caqui

Tomate cereja

Tomate comum

Vagem cozida
PESO (g)

53,0

81,0

85,0

90,0

130,0

80,0

40,0

35,0

120,0

65,0

80,0

73,0

60,0

30,0

42,0

60,0

50,0

60,0

81,0

35,0

36,0

36,0

57,0

63,0

40,0

69,0

42,0

13,0

19,5

11,0

83,0

60,0

40,0

83,0

100,0

130,0

116,0

108,0

70,0

72,0

102,0

72,0

75,0

60,0

83,0

38,0

75,0

70,0

80,0

44,0
MEDIDA CASEIRA

$11 / 2$ colheres de sopa

3 colheres de sopa

$21 / 2$ colheres de sopa

9 colheres de sopa

22 ramos

2 unidades

$1 / 2$ unidade

$1 / 4$ unidade

15 folhas

5 folhas

8 unidades

$61 / 2$ unidades

2 colheres de sopa

3 fatias

2 colheres de sopa

$41 / 2$ colheres de sopa

$11 / 2$ copo americano

$3 / 4$ unidade

$11 / 2$ colher de servir

7 fatias

$3 / 4$ colher de servir

1 colher de servir

$21 / 2$ colheres de sopa

9 unidades

$21 / 2$ unidades

3 ramos

1 colher de servir

1 colher de sopa

$11 / 2$ colher de sopa

2 unidades

15 folhas

3 colheres de sopa

$11 \frac{1}{2}$ colher de sopa

8 folhas

2 unidades

1 unidade

4 colheres de sopa

5 colheres de sopa

10 fatias

3 colheres de sopa

3 unidades

6 colheres de sopa

5 colheres de sopa

5 colheres de sopa

15 folhas

2 colheres de sopa

$21 / 2$ fatias

7 unidades

4 fatias

2 colheres de sopa 


\section{ANEXO6}

Frutas. $(n=41)$

1 porção $=35 \mathrm{kcal}$

\section{ALIMENTOS}

Abacate
Abacaxi
Acerola
Ameixa-preta
Ameixa-vermelha
Banana-prata
Caju
Caqui
Carambola
Cereja
Damasco seco
Fruta do conde
Goiaba
Jabuticaba
Jaca
Kiwi
Laranja-da-baía/seleta
Laranja-pêra/lima espremida para chupar
Limão
Maçã
Mamão formosa
Mamão papaya
Manga bordon
Manga haden
Manga polpa batida
Maracujá (suco puro)
Melancia
Melão
Morango
Nectarina
Pêra
Pêssego
Suco de abacaxi com açúcar
Suco de laranja (puro)
Suco de melão
Suco de tangerina
Suco de uva (industrializado) com açúcar
Tangerina
Uva comum itália
Uvabi

PESO (g)

\begin{tabular}{|c|c|}
\hline 24,0 & $3 / 4$ colher sopa \\
\hline 65,0 & $1 / 2$ fatia \\
\hline 128,0 & 1 xícara das de chá \\
\hline 15,0 & $11 / 2$ unidade \\
\hline 70,0 & 2 unidades \\
\hline 43,0 & $1 / 2$ unidade \\
\hline 81,0 & 1 unidade \\
\hline 50,0 & $1 / 2$ unidade \\
\hline 110,0 & 1 unidade \\
\hline 48,0 & 12 unidades \\
\hline 63,0 & 9 unidades \\
\hline 35,0 & $1 / 4$ unidade \\
\hline 50,0 & $1 / 4$ unidade \\
\hline 68,0 & 17 unidades \\
\hline 66,0 & 2 bagos \\
\hline 60,0 & $3 / 4$ unidade \\
\hline 80,0 & 4 gomos \\
\hline 75,0 & 1 unidade \\
\hline 126,0 & 2 unidades \\
\hline 60,0 & $1 / 2$ unidade \\
\hline 110,0 & 1 fatia \\
\hline 93,0 & $1 / 3$ unidade \\
\hline 55,0 & $1 / 2$ unidade \\
\hline 55,0 & $1 / 4$ unidade \\
\hline 50,0 & 5 colheres sopa \\
\hline 50,0 & 5 colheres das de sopa \\
\hline 115,0 & 1 fatia \\
\hline 108,0 & 1 fatia \\
\hline 115,0 & 9 unidades \\
\hline 69,0 & $3 / 4$ unidade \\
\hline 66,0 & $1 / 2$ unidade \\
\hline 85,0 & $3 / 4$ unidade \\
\hline 83,0 & 1/2 copo plástico \\
\hline 79,0 & 1/2 copo plástico \\
\hline 85,0 & $1 / 2$ copo requeijão \\
\hline 82,0 & 1/2 copo plástico \\
\hline 133,0 & 1/2 copo plástico \\
\hline 84,0 & 6 gomos \\
\hline 50,0 & 11 bagos \\
\hline 50,0 & 4 bagos \\
\hline 50,0 & 4 bagos \\
\hline 70,0 & 1/2 copo plástico \\
\hline
\end{tabular}

OBS: Copo plástico descartável para água (140 ml). 


\section{ANEXO7}

Leguminosas $(n=7)$

1 porção $=55 \mathrm{kcal}$

\section{ALIMENTOS}

Ervilha seca cozida

Feijão branco cozido

Feijão cozido (50 \% de caldo)

Feijão cozido (somente grãos)

Grão de bico cozido

Lentilha cozida

Soja cozida
$\operatorname{PESO}(\mathrm{g})$

72,5

48,0

86,0

50,0

36,0

48,0

43,0
MEDIDA CASEIRA

$21 / 2$ colheres de sopa $1 \frac{1}{2}$ colher de sopa

1 concha

2 colheres de sopa

$1 \frac{1 / 2}{2}$ colheres de sopa

2 colheres de sopa

1 colher de servir

\section{ANEXO8}

Carne Bovina, Suína, Peixe, Frango, Ovos. $(n=31)$ 1 porção $=190 \mathrm{kcal}$

\section{ALIMENTOS}

Atum enlatado tipo "desfiado"
Atum enlatado tipo "sólido"
Bacalhoada
Bife à role
Bife grelhado
Camarão cozido
Camarão frito
Carne cozida
Carne cozida de peru tipo "blanquet"
Carne cozida de peru tipo "rolê"
Carne moída refogada
Espetinho de carne
Frango assado inteiro
Frango filé à milanesa
Frango filé grelhado
Frango sobrecoxa cozida com molho
Hambúrguer caseiro
Hambúrguer industrializado
Lingüiça de porco cozida
Manjuba frita
Merluza cozida
Merluza defumada
Nugget de frango
Omelete simples
Ovo frito
Ovo pochê
Peixe espada cozido
Porco lombo assado
Salame
Salsicha
Sardinha escabeche
a

$\operatorname{PESO}(\mathrm{g})$

\begin{tabular}{|c|c|}
\hline 80,0 & 2 colheres de sopa \\
\hline 90,0 & 2 colheres de sopa \\
\hline 75,0 & $1 / 2$ porção \\
\hline 110,0 & 1 unidade \\
\hline 64,0 & 1 unidade \\
\hline 160,0 & 20 unidades \\
\hline 80,0 & 10 unidades \\
\hline 80,0 & 1 fatia \\
\hline 150,0 & 10 fatias \\
\hline 180,0 & 12 fatias \\
\hline 90,0 & 5 colheres de sopa \\
\hline 92,0 & 2 unidades \\
\hline 100,0 & $\begin{array}{l}1 \text { pedaço de peito ou } \\
1 \text { coxa grande ou } \\
1 \text { sobrecoxa }\end{array}$ \\
\hline 80,0 & 1 unidade \\
\hline 100,0 & 1 unidade grande \\
\hline 100,0 & 1 unidade \\
\hline 90,0 & 1 unidade \\
\hline 90,0 & 1 unidade \\
\hline 50,0 & 1 gomo \\
\hline 106,0 & 10 unidades \\
\hline 200,0 & 2 filés médios \\
\hline 190,0 & 3 filés \\
\hline 72,0 & 4 unidades \\
\hline 74,0 & 1 unidade \\
\hline 100,0 & 2 unidades \\
\hline 100,0 & 2 unidades \\
\hline 100,0 & 1 porção \\
\hline 80,0 & 1 fatia \\
\hline 75,0 & 11 fatias \\
\hline 60,0 & $1 \frac{1 / 2}{2}$ unidade \\
\hline 50,0 & 1 unidade \\
\hline
\end{tabular}




\section{ALIMENTOS}

Cream cheese

Iogurte de frutas

Iogurte natural

Iogurte polpa de frutas

Iogurte polpa de frutas com geléia

Iogurte polpa de frutas "ninho soleil"

Leite em pó integral

Leite semidesnatado "molico"

Leite tipo B

Molho branco com queijo

Queijo-de-minas

Queijo mussarela

Queijo parmesão

Queijo pasteurizado tipo "polenguinho"

Queijo pasteurizado tipo "sandwich in"

Queijo petit suisse de morango

Queijo prato

Queijo provolone

Requeijão cremoso

Ricota

Sobremesa láctea tipo "pudim de leite"

Suflê de queijo

\section{ANEXO9}

Produtos lácteos. $(n=23)$

1 porção $=120 \mathrm{kcal}$

$\operatorname{PESO}(\mathrm{g})$

77,5
140,0
400,0
120,0
130,0
120,0
30,0
278,0
182,0
62,5
50,0
45,0
30,0
35,0
40,0
90,0
40,0
35,0
45,0
100,0
90,0
50,0

ANEXO10

Óleos e Gorduras. (n=14)

1 porção $=73 \mathrm{kcal}$

\section{ALIMENTOS}

Azeite de dendê

Azeite de oliva

Bacon (gordura)

Banha de porco

Creme vegetal

Halvarina

Manteiga

Margarina culinária

Margarina líquida

Margarina vegetal

Óleo vegetal composto de soja e oliva

Óleo vegetal de girassol

Óleo vegetal de milho

Óleo vegetal de soja

\section{PESO (g)}

9,2
7,6
7,5
7,0
14,0
19,7
9,8
10,0
8,9
9,8
8,0
8,0
8,0
8,0

MEDIDA CASEIRA

$21 / 2$ colheres de sopa

1 pote

2 copo de requeijão

1 pote

1 pote

1 pote

2 colheres de sopa

2 colheres de sopa

$1 \frac{1}{2}$ copo de requeijão

$2 \frac{1}{2}$ colheres de sopa

$1 \frac{1 / 2}{2}$ fatia

3 fatias

3 colheres de sopa

2 unidade

2 fatias

2 potes

2 fatias

1 fatia

$1 \frac{1 / 2}{2}$ colher de sopa

2 fatias

1 pote

1 fatia

\section{MEDIDA CASEIRA}

$3 / 4$ colher de sopa

1 colher de sopa

$1 / 2$ fatia

$1 / 2$ colher de sopa

1 colher de sopa

1 colher de sopa

$1 / 2$ colher de sopa

$1 / 10$ tablete

1 colher de sopa

$1 / 2$ colher de sopa

1 colher de sopa

1 colher de sopa

1 colher de sopa

1 colher de sopa 


\section{ANEXO11}

Açúcares. (n= 8)

1 porção $=110 \mathrm{kcal}$

\section{ALIMENTOS}

Açúcar mascavo fino

Açúcar mascavo grosso

Açúcar refinado

Dextrosol

Doce industrializado tipo goiabada

Glucose de milho (Karo)

Mel

Nidex
PESO (g)

25,0

27,0

28,0

32,5

45,0

40,0

37,5

30,0
MEDIDA CASEIRA

1 colher de sopa

$11 / 2$ colher de sopa

1 colher de sopa

$2 \frac{1}{2}$ colher de sopa

$1 / 2$ fatia

2 colheres de sopa

$21 / 2$ colheres de sopa

6 medidas 